\title{
Macroinvertebrates and its impact in assessing water quality of riverine system: A case study of Mahanadi river, Cuttack, India
}

\author{
Ishita Ganguly* \\ Amity Institute of Forestry and Wildlife, Amity University, Noida 201313 (Uttar Pradesh), \\ India. \\ Lipika Patnaik \\ Environmental Science Laboratory, Department of Zoology, Ravenshaw University, \\ Cuttack-753003 (Odisha), India \\ Susri Nayak \\ Environmental Science Laboratory, Department of Zoology, Ravenshaw University, \\ Cuttack-753003 (Odisha), India
}

*Corresponding author. E-mail: ishitaganguly23@gmail.com

\begin{abstract}
The aim of this study was to identify the diverse macroinvertebrates present in river Mahanadi, Cuttack in India and to evaluate the role of macroinvertebrates in assessing river water quality and pollution level. We conducted field study of the river at Cuttack $\left(85^{\circ}\right.$ 46 '21.29" E $20^{\circ} 28^{\prime} 15.81^{\prime \prime} N$ \& 85 49'45.23" E 20³0'50.00” N) during 2013-2014 and collected aquatic invertebrate samples from 12 stations on river basin. The samples were analysed to explore the various families of Macroinvertebrates communities present in river Mahanadi, to examine the status of water quality of the river using biological indicators, to determine whether there are relationships between water chemistry and presence of typical macroinvertebrates and to develop a Macroinvertebrates based index to bioassessment of Mahanadi River. A total of 484 taxa were identified and about 244 taxa of bivalves and 184 taxa of gastropods were collected. Presence of high number of pollution tolerant taxa and pollution sensitive taxa (Ephemeroptera, Plecoptera, Tricoptera and Chironomidae) indicated increased risk of water pollution and calculated biotic score (8), biological monitoring working party (BMWP) score (52), average score per taxa (ASPT) score (4) and macroinvertebrate-based index (MBI) value indicated moderate pollution level in the river. We recorded $\mathrm{pH}$, total hardness, dissolved oxygen (DO), biological oxygen demand (BOD), total nitrite, chloride and total phosphate of water and physicochemical parameters supported the values of biological assessment of water quality. Studying macaroinvertebrates helped to gain knowledge about aquatic faunal biodiversity in river Mahanadi and to develop a method for diagnosis of the health of river ecosystem and for measuring water pollution level.
\end{abstract}

Keywords: Bioassessment, Ecosystem health, Macroinvertebrates, Mahanadi

\section{INTRODUCTION}

Macro invertebrates are organisms which are large enough to be seen with the unaided eye and without vertebral column, most abundant and diverse group of animals found in freshwater which include flies, Snails, mussels, worms, nematodes and crustaceans are used for biomonitoring of water quality. Mac Neil et al., (2002) have recognized the concept that macro invertebrate families are very diverse, sensitive, population to pollution of a water body and may be suitable for assessment of severity of contamination of water pollution. An increase or decrease of macroinvertebrate population in water body indicates pollution, presence of stress factors and damage to the ecosystem. This biological assessment of water decodes more information than chemical moni-

\section{Article Info}

DOI:10.31018/jans.v10i3.1817

Received: June 30, 2018

Revised: July 25, 2018

Accepted: August 5, 2018

\section{How to Cite}

Ganguly, I. et al. (2018).

Macroinvertebrates and its impact in assessing water quality of riverine system: A case study of Mahanadi river, Cuttack, India. Journal of Applied and Natural Science, 10(3): 958 - 963 
are the most widely used organisms in freshwater biomonitoring and human impact on riverine water pollution. Aquatic environments are being modified by anthropogenic activities regarding their biological, physical, and chemical conditions and many developed countries are using Macroinvertebrates as bioindicators as they are included in national and technical standards of water quality monitoring in Europe. Biological assessment of river water quality has become a widespread field of research including US, Canada, UK, Australia, New Zealand, The European Union and the protocols have been implemented successfully and East Asian countries are now putting effort to implement macro invertebrate biomonitoring protocol (Morse et al., 2007). Biological monitoring has advantages over chemical monitoring because it integrates responses to a range of pollutants occurring over different times (Jüttner et al., 2003; Emere and Narisu, 2007) Macro invertebrates serves a pivotal role to understand ecological status of water body using biological indicator as a tool and provide accurate measures of stream health. Within the organisms commonly used as biological indicators, benthic macro invertebrates stand out as ideal due to: relatively low mobility and long life cycles, reflecting temporal patterns and local conditions; high diversity, abundance and consequently in providing a wide range of responses to different environmental pollution agents, large size and identification at high taxonomic (such as family) resolution, well standardized and low-cost methodologies, temporal and spatial stability and power to reflect changes in ecosystem processes. Macro invertebrates are important bioindicators because of their limited locomotory abilities, their attachment to solid substrates, and their relatively long-life cycles. Thus, these organisms are well suited for monitoring water quality in flowing water. The macro benthic population is highly influenced by physicochemical changes, availability of the substratum, food and predation and certain types of human activities. The density of macro invertebrates also fluctuates widely with seasonal changes. Macro invertebrates are an integral part of an aquatic environment and are of ecological and economic importance as they maintain various levels of interaction between the community and the environment (Anderson and Sedel, 1979).

The aim of this study was to explore the various families of Macroinvertebrates communities present in river Mahanadi, to examine the status of its water quality using biological indicators, to understand the relationship of chemical parameters and presence of macroinvertebrates and to develop a macroinvertebrates-based index for the bioassessment of the river.

\section{MATERIALS AND METHODS}

The study area is in Mahanadi river, Cuttack (Odisha) throughout the coordinates of $85^{\circ}$
46'21.29" E 20²8'15.81" N\& 8549'45.23" E $20^{\circ}$ $30^{\prime} 50.00$ " N (Figure 1.The river originates from Madhya Pradesh of central India and carries over $66 \mathrm{~km}^{3}$ of water (Rao 1979) into Bay of Bengal near Paradip. Mahanadi is one of the major seasonal rivers in East Central India and It drains an area of around $141,600 \mathrm{~km}^{2}$ and $858 \mathrm{~km}$ long stretch which flows through the states of Chhattisgarh and Odisha. The river is mainly used for fishing, propagation of aquatic life, prawn culture, transport \& irrigation. We boarded the boat from Bidanasi ferry ghat, Cuttack and travelled into the river for collecting samples from various stations upstream and downstream. We collected samples using kick-sampling method (Abel, 1996) from following 12 stations of the river basin: St-1: Dhabaleshwar, St-2: Mancheswar, St-3: Prasanapur, St-4: Kansaripatra, St-5: Kundakhai Pathar, St-6: Medakhia Patha, St-7: Dihasani, Nuapatna, St-8: Bhuasuni, St-9: Patheibara, St10: Narangbasta, St-11: Nuadhia, St-12: Balikuda (Fig.1).

Biological sampling: We collected macroinvertebrates from December 2013 to August 2014 and the samples were taken with movement across the stream, which avoided recovery of invertebrates specific to one microhabitat (Ziglio et al., 2006). A 3-minute kick sample was taken as described in Abel, (1996) from each station. Several techniques for monitoring macroinvertebrates exist, but kick sampling was considered appropriate as the water was shallow and it was inexpensive (Mason, 2002; Ziglio et al., 2006). To standardize the method sampling time (3 minutes), net size, person sampling was kept constant. Sample bottles were taken to lab by adding preservatives (formaldehyde, $70 \%$ ethanol) as immediate identification was not possible.

Water sampling for chemical monitoring (Random water sampling from select stations): Water samples were collected from depth of $30 \mathrm{~m}$ an average from the river at each station. For analysis of dissolved oxygen (DO) of water samples by Winkler's method the sample bottles were fixed immediately by adding fixatives in biological oxygen demand (BOD) bottles of $300 \mathrm{ml}$ capacity. Physical parameters and chemicals parameters of water was analysed in the laboratory following standard method of American public health association (APHA, 1985). Water samples were taken from following places: St-1: Dhabaleshwar, St-2: Mancheswar, St-3: Prasanapur, St-4: Kansaripatra, St-5: Kundakhai Pathar, St-6: Medakhia Patha, St-7: Dihasani, Nuapatna, St-8: Bhuasuni, St-9: Patheibara, St-10: Narangbasta, St-11: Nuadhia, St-12: Balikuda.

Biotic Index calculation method: We followed the method developed by William M. Beck, Jr. (1953-1954) in response to the need for biological measure of stream pollution. This method is 
based on the classification of selected macroinvertebrates into categories depending on their response to organic pollution. We divided macroinvertebrates into different groups based on their ability to tolerate organic pollution.

Class I - pollution sensitive

Class II - moderately tolerant

Class III - pollution tolerant

Biotic Index $=2(\mathrm{n}$ Class I $)+($ Class II $)$

Where, $n=$ number of taxa

BMWP (Biological Monitoring Working Party) method: The BMWP Score is the sum of the values for all families present in the sample. This method provided a score for each macroinvertebrate family which is dependent on its sensitivity to organic pollution (Mason, 2002). The BMWP system considered the sensitivity of invertebrates to pollution and families were assigned a score between 1 and 10 accordingly (Biological Monitoring Working Party, 1978).

ASPT (Average Score Per Taxa) score: It was calculated as ASPT = BMWP Score/Number of scoring taxa. A high ASPT was considered indicative of a clean site containing large numbers of high scoring taxa (Armitage et al., 1983). The table shown below is adapted from Chapman, 1996 (Table 1).

Ephemeroptera,Plecoptera, Trichoptera (EPT) richness method: The total number of mayfly, stonefly and caddisfly families within a sample was classified and calculated (Vinson and Hawkins 1996). These taxa were considered least tolerant to organic pollution, therefore a sample with high EPT richness was considered indicative of good quality water.

Macroinvertebrate based Index (MBI) method: Based on EPT richness score, we calculated the macroinvertebrate-based index score. We followed the following table to calculate the value. Tentative Quality Ratings: Revised 2004.

\section{RESULTS}

Composition of macro invertebrate species present in Mahanadi: A total of 484 taxa were identified from study sites and preserved with $70 \%$ ethanol and we preserved the samples in our laboratory (Image 1). Maximum abundance and diversity occurred in the stable zones with moderate water current velocity. Diverse families of gastropods and bivalves were found, and species abundance was very high. Heterogeneity among gastropods was remarkable in Mahanadi River (244 taxa of bivalves \& 184 taxa of snails). The river also contained thirteen species of dragonfly (larval stages are found) and midges (Chironomous).Numerous aquatic worms were present which were found mostly in winter. The presence of maximum tolerant species was found, and their number fluctuated with variation in temperature. Winter months revealed the larval stag-

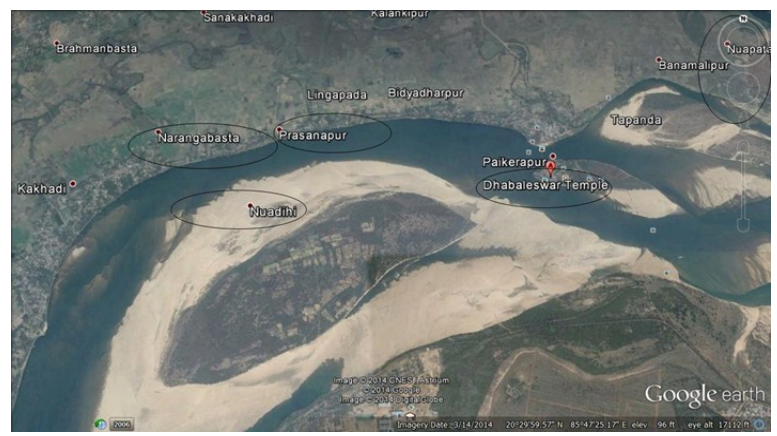

Fig. 1. Area of study at river Mahanadi, Cuttack (Odisha).

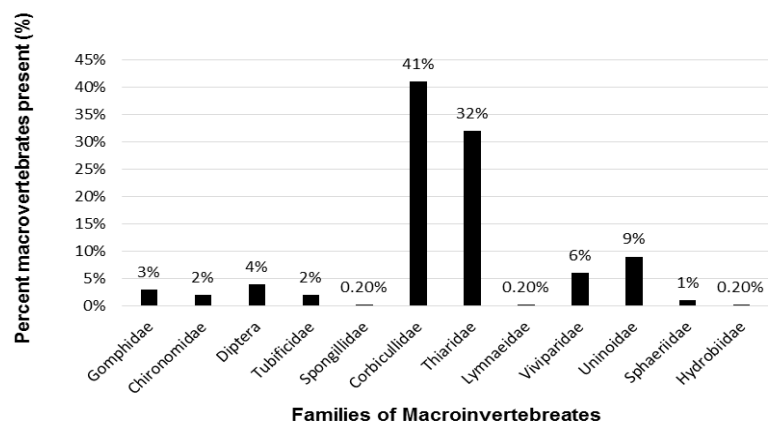

Fig. 2. Presence of macro invertebrates in Mahanadi river, Cuttack.

es of invertebrates including Chironomidae, Diptera, Gastropoda. Family- Corbiculidae has the maximum occupancy with $41 \%$ of the total macroinvertebrate population which is followed by Thiaridae (32\%), Unionoidae (9\%),Viviparidae $(6 \%)$ and other insect families in Mahanadi river (Figure 2). We have found maximum diversity of macroinvertebrates in Nuapatna, Bhuasuni and KundakhiaPathar among all other stations (Table 3).We recorded 68\% Perreysiacorrugata, 16\% Dragon fly, 7\% Corbicula strietella, 7\% Tarebialineata and $2 \%$ Sphaerium sp. from Nuapatna; $46 \%$ Corbicula strietella, 29\% Melanoides tubeculata, 8\% Tarebia lineata, 5\% Perreysia corrugata, 3\% Diptera larva, $1 \%$ round worms, $1 \%$ chironomous larva, $1 \%$ Bellamyabengalensis and $1 \%$ coleoptera larva from Bhuasuni; 37\% Corbicula strietella, 31\% Tarebia lineata, $11 \%$ Perreysia corrugata, $12 \%$ Diptera larva, 2\% True fly, 4\% Spherium sp. and $1 \%$ Progomphus serenus from KundakhiaPathar. We studied ecology of macroinvertebrates and summarized the result in the given table (Table 4).

Biotic Indices calculations: We calculated biotic index value which was 8 and it indicated "moderate pollution" according to biotic index card range. Maximum pollution tolerant species were present on all sites overall in Mahanadi which comes under class III. In our study, Mayfly belonged to class I, Caddishfly belonged to class II, Trichoptera belonged to class I, Clams from class II, Dragon fly class II and Beetle larva class III. Calculated score of Biological monitoring working 
Table 1. ASPT indication of river water quality.

\begin{tabular}{|c|c|c|c|}
\hline \multicolumn{2}{|l|}{ Water quality } & \multicolumn{2}{|c|}{ ASPT score } \\
\hline \multirow{5}{*}{$\begin{array}{l}\text { Excellent } \\
\text { Very good } \\
\text { good } \\
\text { moderate } \\
\text { poor }\end{array}$} & \multicolumn{3}{|c|}{$>5.4$} \\
\hline & \multicolumn{3}{|c|}{$4.8-5.4$} \\
\hline & \multicolumn{3}{|c|}{$4.3-4.8$} \\
\hline & \multicolumn{3}{|c|}{$3.6-4.3$} \\
\hline & \multicolumn{3}{|c|}{$3.0-3.6$} \\
\hline \multicolumn{4}{|l|}{ Table 2. MB } \\
\hline Quality & $\begin{array}{c}\text { Taxa } \\
\text { richness }\end{array}$ & $\begin{array}{c}\text { EPT } \\
\text { richness }\end{array}$ & MBI \\
\hline Excellent & $>=14$ & $>=5$ & $<=4.35$ \\
\hline Good & $12-13$ & 4 & $4.36-5.00$ \\
\hline Fair & $9-11$ & 3 & $5.01-5.70$ \\
\hline Poor & $7-8$ & 2 & $5.71-6.25$ \\
\hline Very Poor & $<=6$ & $0-1$ & $>=6.26$ \\
\hline
\end{tabular}

party (BMWP) was 52 which indicated class III range of water quality means moderate pollution level. We calculated Average Score Per Taxa (ASPT) score and the value of 4.0 indicated the moderate level of water pollution in Mahanadi river. Calculated Ephemeroptera, Plecoptera, Trichoptera (EPT) Richness level was 3.77 and taxa richness range was between 9-11 and calculated macroinvertebrate-based index value (MBI) ranged from 5.01-5.70 which indicated fair pollution level according to matrix.

Physico-chemical properties of water: We calculated the physical and chemical characteristics of water in our study area from 12 stations (St-1: Dhabaleshwar, St-2: Mancheswar, St-3: Prasanapur, St-4: Kansaripatra, St-5: Kundakhai Pathar, St-6: Medakhia Patha, St-7: Dihasani, Nuapatna, St-8: Bhuasuni, St-9: Patheibara, St-10: Narangbasta, St-11: Nuadhia, St-12: Balikuda) and summerised the values in the table given (Table 5 ). We correlated the physico-chemical parameters of water with the presence of macroinveretebrates in each sites and higher values of total hardness, phosphate, nitrite and chloride supported the presence of aquatic invertebrates.

\section{DISCUSSION}

Macroinvertebrates are found in all aquatic habitats and diverse environments require different sampling strategies. Biomonitoring approach using macroinvertebrates should be cost effective and sampling method should provide potential information about water environment, pollution level and further management (Hughes and Peck, 2008). Ramakrishnan, N. (2003) investigated the bio-monitoring approach for water quality assessment in two water bodies situated at Tiruvannamalai, Tamilnadu. In that study he included several biological communities and various hydrochemical factors like water temperature, $\mathrm{pH}$, alkalinity, free Carbon di oxide, dissolved oxygen, nitrate, phosphate and calcium to assess the water quality of specific water bodies. In our study, we investigated macroinvertebrate communities in
Table 3. Macroinvertebrates collected from our study area from 2013-2014, Mahanadi

\begin{tabular}{|c|c|c|c|}
\hline $\begin{array}{l}\text { Sl. } \\
\text { No. }\end{array}$ & Macroinvertebrates & Number & Total \\
\hline St 1 & $\begin{array}{l}\text { Corbicula strietella } \\
\text { Mayfly }\end{array}$ & $\begin{array}{l}14 \\
1\end{array}$ & 15 \\
\hline St 2 & $\begin{array}{l}\text { Physellagyrina } \\
\text { Bellamya bengalensis } \\
\text { Lymnaea acuminate } \\
\text { Round worms } \\
\text { (nematodes) } \\
\text { Chironomous } \\
\text { Coleoptera larva } \\
\text { Dragonfly (Progomphus) }\end{array}$ & $\begin{array}{l}1 \\
1 \\
1 \\
4 \\
10 \\
9 \\
2\end{array}$ & 28 \\
\hline St 3 & $\begin{array}{l}\text { Diptera larva } \\
\text { Adult fly (True fly) }\end{array}$ & $\begin{array}{l}13 \\
2\end{array}$ & 15 \\
\hline St 4 & Dragonfly (Progomphus) & 4 & 4 \\
\hline St 5 & $\begin{array}{l}\text { Lymnaea acuminate } \\
\text { Corbicula strietella } \\
\text { Tarebia lineatia } \\
\text { Melanoides tuberculata }\end{array}$ & $\begin{array}{l}3 \\
139 \\
14 \\
91\end{array}$ & 247 \\
\hline St 6 & Perreysia corrugata & 2 & 2 \\
\hline St 7 & Dragonfly (Progomphus) & 2 & 2 \\
\hline St 8 & $\begin{array}{l}\text { Corbicula strietella } \\
\text { Perreysia corrugate } \\
\text { Bellamya bengalensis } \\
\text { Diptera larva }\end{array}$ & $\begin{array}{l}16 \\
6 \\
2 \\
4\end{array}$ & 28 \\
\hline St9 & $\begin{array}{l}\text { Progomphus serenus } \\
\text { Perreysia corrugata } \\
\text { Tarebia lineatia } \\
\text { Corbicula strietella } \\
\text { Planorbisexustus } \\
\text { Sponge }\end{array}$ & $\begin{array}{l}2 \\
12 \\
39 \\
34 \\
1 \\
1\end{array}$ & 89 \\
\hline St 10 & $\begin{array}{l}\text { Tarebia lineatia } \\
\text { Corbicula strietella } \\
\text { Dragonfly (Progomphus) }\end{array}$ & $\begin{array}{l}4 \\
9 \\
5\end{array}$ & 18 \\
\hline St 11 & $\begin{array}{l}\text { Dragonfly (Progomphus) } \\
\text { Corbicula strietella } \\
\text { Perreysia corrugata } \\
\text { Tarebialineatia }\end{array}$ & $\begin{array}{l}2 \\
7 \\
11 \\
9\end{array}$ & 29 \\
\hline St 12 & $\begin{array}{l}\text { Perreysia corrugate } \\
\text { Anax junius }\end{array}$ & $\begin{array}{l}5 \\
2\end{array}$ & 7 \\
\hline
\end{tabular}

river Mahanadi and analyzed the water samples and their physical and chemical properties and correlated their presence with species abundance which helped to determine river water quality. Similarly, Czerniawska-Kusza I., (2005) compared modified biological monitoring working party score system and several biological indices based on macroinvertebrates for water-quality assessment. Duran, M. (2006) assessed water quality of Behzat Stream by using benthic macroinvertebrates and physicochemical parameters in Turkey. It was shown that eutrophication of fresh water and coastal marine ecosystems were considered as global threats (Walter and Val, 2012). Human activities have significantly altered the fluxes of growth-limiting nutrients in water bodies. Macneil et al. (2002) recognized the concept that macro invertebrate families that they were very diverse, sensitive, population to pollution of a water body and may be suitable for assessment of severity of contamination of water pollution. Our study showed that maximum number of pollution toler- 
Table 4. Macroinvertebrates categories by habitat preferences, feeding groups and tolerance limit.

\begin{tabular}{|c|c|c|c|c|}
\hline $\begin{array}{l}\text { Hierarchical position in } \\
\text { taxonomy }\end{array}$ & Common Name & $\begin{array}{l}\text { Functional Feed- } \\
\text { ing Group (FFG) }\end{array}$ & $\begin{array}{l}\text { Stressor Toler- } \\
\text { ance Value (STV) }\end{array}$ & Habitat \\
\hline Nematoda (Phylum) & Roundworms & PA, PI, SH & 5 & LO, LE \\
\hline Gastropoda (Class) & Snails & SC & 7 & LE, LO \\
\hline Bivalvia (Class) & Mussels and Clams & $\mathrm{CF}$ & 7 & LE, LO \\
\hline Baetidae (Family) & Small minnow mayflies & CG, SC & 4 & LO \\
\hline Aeshnidae (Family) & Darner dragonflies & PR & 3 & LE, LO \\
\hline Gomphidae (Family) & Club-tail dragonflies & PR & 1 & LO, LE \\
\hline Philopotamidae (Family) & Finger-Net caddisflies & $\mathrm{CF}$ & 3 & LO \\
\hline Chironomidae (Family) & Non-Biting Midges & CG & 6,8 & LE \\
\hline
\end{tabular}

PA:Parasite; PI: Piercer; SH: Shredder; SC: Scraper; CF: Collector-filterer; CG: Collector-gatherer; PR: Predator; LO: Lotic; LE: Lentic

Table 5. Physico-chemical parameters of water in Mahanadi River, Cuttack.

\begin{tabular}{cccccccc}
\hline SI. No. & pH & Hardness & DO & Phosphate & Nitrite & Chloride & Conductivity \\
\hline St-1 & 7.64 & 73.2 & 7.98 & 0.09 & 0.26 & 28.0 & 1.87 \\
St-2 & 7.58 & 74.0 & 7.92 & 0.12 & 0.38 & 24.6 & 1.53 \\
St-3 & 8.08 & 94.0 & 5.88 & 0.29 & 0.46 & 24.5 & 0.245 \\
St-4 & 8.19 & 96.5 & 1.86 & 0.3 & 0.32 & 22.5 & 0.09 \\
St-5 & 8.2 & 111.0 & 3.55 & 0.14 & 0.37 & 24.0 & 0.143 \\
St-6 & 8.22 & 105.0 & 5.19 & 0.17 & 0.37 & 18.2 & 0.08 \\
St-7 & 8.0 & 90.0 & 8.14 & 0.23 & 0.47 & 34.0 & 1.7 \\
St-8 & 8.07 & 92.0 & 8.16 & 0.28 & 0.38 & 26.0 & 1.55 \\
St-9 & 8.22 & 121.0 & 2.73 & 0.16 & 0.44 & 10.1 & 2.3 \\
St-10 & 7.96 & 88.0 & 2.98 & 0.18 & 0.33 & 12.0 & 2.2 \\
St-11 & 8.12 & 84.0 & 2.97 & 0.19 & 0.36 & 18.0 & 2.22 \\
St-12 & 8.17 & 85.2 & 2.98 & 0.22 & 0.42 & 21.0 & 2.23 \\
\hline
\end{tabular}

ant species were present in river Mahanadi. Presence of diverse groups of Gastropods and Diptera larva indicated moderate water quality. Even moderate pollution tolerant taxa like Odonata and Trichoptera and pollution sensitive taxa like Ephemeroptera (Mayfly) were also present in the study sites. BMWP score, ASPT score and Biotic index indicated moderate level of water in our study area (Biological Monitoring Working Party, 1978). Biological analysis depicts a more accurate scenario of water bodies than chemical analysis. Water quality was checked by chemical tests and inorganic reactions in laboratory and data were correlated with the biological sampling data. Nitrite, phosphate, chloride, total hardness and $\mathrm{pH}$ of water greatly influenced the biological diversity of water bodies. High range of total phosphate and nitrite confirmed the abundance and richness of invertebrate species within our study area. Larva to adult, many stages of invertebrate life-cycle revealed detail water quality index of river Mahanadi. Monthly sampling of macroinvertebrates helped to assess water quality accurately with the development of biotic index. This has been proven as an important tool to assess water pollution level. Besides, the river is extensively used for fishing, transport, washing and cleaning purpose which are destroying animal life in water. Presence of high number of pollution tolerant taxa justified this process of pollution. Huge diversification has been found among these tolerant species. Many Gastropod snails and Bivalves were identified from our study area. Water quality assessing parameters were tested to find any correlation with the richness of macroinvertebrates found in our study. Total Hardness is high at all the rich zones. The data showed diversity among macroinvertebrates present in hard water where the total hardness is more than $>80 \mathrm{mg} / \mathrm{lt}$. Where the Conductivity was reversely proportionate with the richness of macroinvertebrate species found. Total Phosphate and nitrite both were high, and it indicated that our study area was a rich habitat for macroinvertebrates. A nearly constant $\mathrm{pH}$ of 8 showed maximum abundances of macroinvertebrates. Higher Dissolved oxygen (DO)mg/lit value was also correlated with the presence of maximum larval stages. Chloride proportionally increased with the species richness. Nuapatna, Bhuasuni, Dihasahi, Kundakhia Pathar were the places in Mahanandi river where maximum species diversity and richness were found.

\section{Conclusion}

Use of kick sampling method and kick-net devices for collecting macroinvertebrates, taxonomic identification, Ephemeroptera-Placoptera-TrichopteraChironomidae analysis and evaluation of biotic scores seemed to be useful methods for biomonitoring of river water and its cost-effectiveness, potential for gathering vast level of information of steam health makes it completely unique. We identified aquatic organisms up to species level using zoological nomenclature system. This study results provides knowledge about diversified aquatic fauna present in Mahanadi, their occur- 
rence, distribution pattern, feeding groups and habitats. Study of water chemical properties supported the presence and relative abundance of macroinvertebrates in selected stations under study. Overall pollution level indicated by macroinvertebrates community was moderate in Mahanadi and river water quality was medium to fair according to biotic index calculation score. Although, richness of pollution tolerant taxa (Gastropoda and Bivalvia) and pollution sensitive taxa (Chironomidae) indicated accumulation of waste material in the river basin and increased risk of pollution in near future. Based on biological assessment further management plan can be developed to improve water quality in Mahanadi river and this method can be applied to several other places to reduce water pollution level in riverine systems.

\section{ACKNOWLEDGEMENTS}

We thank Dr.Tulika Biswas and Zoological Survey of India, Kolkata for identification of samples collected for this study and providing reports sincerely during period of study. We also thank our master's students to help in data collection during field studies, Anupama Pati, SashwataPriyadrshini and Anil Dixit. We were thankful Environment biotechnology laboratory, Ravenshaw University, Cuttack for facilitating infrastructure and biological and chemical analysis of samples.

\section{REFERENCES}

1. Abel, P. D. (1996). Water Pollution Biology. Taylor and Francis, London.

2. Anderson, N.H. andSedell, J.R. (1979). Detritus Processing by Macroinvertebrates in Some Ecosystems.Ann. Rev. Entomol 24:357-377.

3. APHA (1985). Standard Methods for the Examination of Water and Wastewater. American Public Health Association. New York, USA. 16th ed. pp 1268.

4. Armitage, P. D., Moss, D., Wright, J.F. and Furse, M.T. (1983). ThePerformance of a New Biological Quality Score SystemBased on Macroinvertebrates Over A Wide Range of Unpol-Luted Running Water Sites. Water Research 17: 333-347.

5. Baker, A., Inverarity,R., Charlton, M. and Richmond, S. (2003). Detecting RiverPollution Using Fluorescence Spectrophotometry: Studies from The Ouseburn, NE England. Environmental Pollution, 124:57- 70

6. Bedoya, D., Novotny, V. andManolakos, E.S. (2009). Instream and Offstream Environmental Conditions and Stream Biotic Integrity: Importance of Scale and Site Similarities for Learning and Prediction. Ecol Model 220: 2393-2406.

7. Biological Monitoring Working Party. (1978). Final Report: Assessment and Presentation of the Biological Quality of Rivers in Great Britain. BMWP, Department of the Environment, London.

8. Bonada, N., Prat, N., Resh, V.H. and Statzner, B.
(2006). Developments in aquatic insect Biomonitoring: A Comparative Analysis of Recent Approaches. Annual Review of Entomology 51: 495-523.

9. Chapman, D. (1996). Water Quality Assessments: A Guide to the Use of Biota, Sediments and Water in Environmental Monitoring. 2nd Edition, Chapman and Hall Ltd., London, 651. http://dx.doi.org/10.4324/ noe0419216001

10.Czerniawska-Kusza, I. (2005). Comparing modified biological monitoring working party score system and several biological indices based on macroinvertebrates for water-quality assessment. Limnologica 35 (3):169-176

11.Duran, M. (2006). Monitoring Water Quality Using Benthic Macroinvertebrates and Physicochemical Parameters of Behzat Stream in Turkey. Polish Journal of Enviromental Studies15(5): 709-717.

12.Emere, M.C and Narisu, C.E. (2007). Macroinvertebrates as indicators of water quality of an urbanized stream in Kaduna, Nigeria. Journal of Fisheries International 2(2), 152-157.

13.Faulkner, H., EdmonsBrown, V. and Green, A. (2000). Problems of Quality in Diffusely Polluted Urban Streams The Case of Pymme's Brook, North London. Environmental Pollution 109, 91-107.

14. Hughes, R. M., and Peck, D. V. (2008). Acquiring data for large aquatic resource surveys: the art of compromise among science, logistics, and reality. Journal of the North American Benthological Society 27,837-859.

15.Jüttner, I., Sharma S., DahalB.M. andOrmerod, S.J. (2003).Diatoms as Indicators of Stream Quality in The Kathmandu Valley and Middle Hills of Nepal And India.Freshwater Biology 48: 2065-2084.

16.Macneil, C., Dick, J.T.A., Gibbins, C., Elwood R.W. and Montgomery, I.A. (2002). A Reappraisal Of The Gamma-Rus:AsellusRatio As An Index Of Organic Pollution. Rivers. Water Research 36: 75-84

17.Mason, C.F. (2002). Biology of Freshwater Pollution. 4th Ed. New York, NY, USA: Prentice Hall.

18.Morse, J.C., Bae, Y.J., Munkhjargal, G., Sangpradub, N., Tanida, K., Vshivkova, T.S., Wang, B., Yang, L. and Yule, C.M., (2007). Freshwater Biomonitoring with Macroinvertebrates in East Asia. Frontiers in Ecology and the Environment 5, 33-42

19.Ramakrishnan, N. (2003). "Bio-Monitoring Approaches For Water Quality Assessment In Two Waterbodies At Tiruvannamalai, Tamil Nadu India". In: Martin J. Bunch, V. Madha Suresh and T. Vasantha Kumaran, eds., Proceedings of the Third International Conference on Environment and Health, Chennai, India. pp 374-385.

20.Vinson, M.R. and Hawkins, C.P. (1996). Effects of sampling area and subsampling procedure on comparisons of taxa richness among streams. Journal of the North American Benthological Society 15 (3): pp. 392-399.

21.Walter, K. D. and Val, H. S. (2016). Nitrogen, Phosphorus, And Eutrophication in Streams. Inland Waters 6, Pp. 155-164.

22.Ziglio, G., Siligardi, M. andFlaim, G. (2006). Biological Monitoring of Rivers. John Wiley \& Sons, Ltd, Ltd, The Atrium, Southern Gate, Chichester, West Sussex, England. 